\title{
Associação entre a presença da proteína p53 e 0 grau de diferenciação em carcinomas ductais invasivos de mama
}

\author{
Association of p53 protein expression and degree of differentiation in infiltrating ductal breast \\ carcinomas
}

Márcia Sanae Siroma ${ }^{1}$, Fausto Farah Baracat ${ }^{2}$

\section{RESUM0}

\begin{abstract}
Objetivo: avaliar a expressão da proteína p53 no carcinoma de mama ductal invasivo e avaliar a sua associação com o grau histológico e o grau nuclear. Métodos: foram incluídas sessenta e cinco mulheres atendidas consecutivamente, entre julho de 1999 e julho de 2001. Todas tiveram diagnóstico de carcinoma primário de mama ductal invasivo. As pacientes foram primeiramente tratadas por terapia cirúrgica conservadora ou mastectomia. Nenhuma paciente recebeu terapia neoadjuvante. Os espécimes cirúrgicos dos tumores foram fixados em formalina a 10\%, posteriormente incluídos em parafina e conservados para análise imuno-histoquimica. A expressão da proteína p53 foi avaliada. Foi utilizado o anticorpo primário monoclonal anti-humano p53 DO - 7 (DAKO). As distribuições das frequiências foram avaliadas pelo teste do $\chi^{2}$. $\mathrm{O}$ valor $\mathrm{p}<0,05$ foi considerado significante. Resultados: a expressão da p53 foi detectada em 24 (36,9\%) dos 65 carcinomas. Entre os casos com expressão da proteína, $13(54,2 \%)$ tinham alto grau histológico (grau III). Oito casos (33,3\%) tinham grau II e, 3 ( $12,5 \%$ ) foram de grau I. Na análise do grau nuclear, entre os casos que expressaram a proteína foram observados $13(54,2 \%)$ grau 3, 9 casos $(37,5 \%)$ grau 2 e dois casos $(8,3 \%)$, grau 1 . A expressão da proteína p53 foi freqüente nos carcinomas com alto grau histológico e nuclear. Conclusão: a expressão da p53 esteve associada com grau histológico de forma significativa. Por outro lado, o grau nuclear não esteve relacionado significativamente com a expressão da p53.
\end{abstract}

PALAVRAS-CHAVE: Proteína supressora de tumor p53; Oncogenes; Prognóstico; Carcinoma ductal de mama; Neoplasias mamárias

\section{ABSTRACT}

Purpose: to assess p53 protein expression in infiltrating ductal breast carcinoma and to analyze its association with histological and nuclear grade. Methods: sixty-five consecutive females who were diagnosed with primary infiltrating ductal breast tumor from July 1999 to July 2001 were included in the present study. Mean patient age at diagnosis was 69.2 years (range 41 -90). All patients were first treated with surgical therapy, conservative surgery or mastectomy. None of the patients received any preoperative adjuvant therapy. Resected breast tumor specimens were fixed in $10 \%$ formalin, paraffin embedded, and conserved for immunohistochemical analysis. p53 protein expression was evaluated. Primary monoclonal anti-human p53 antibody DO-7 (DAKO) was used. Frequency distributions were tested by the $\chi^{2}$ test. A level of p<0,05 was considered significant. Results: p53 expression was detected in $24(36,9 \%)$ of 65 carcinomas. Of the cases with protein expression, $13(54,2 \%)$ were high or histological grade III, $8(33,3 \%)$, were grade II, $3(12,5 \%)$ were grade I. On nuclear grade analysis, of the cases with protein expression, $13(4,2 \%)$ were nuclear grade III, $9(37,5 \%)$ were grade II and $2(8,3 \%)$ were grade I. p53 expression was frequent in carcinomas with high histological and nuclear grades. Conclusions: p53 expression was significantly associated with the histological grade. On the other hand, nuclear grade was not significantly related to p53 expression.

KEYWORDS: Tumor supressor protein p53; Oncogenes; Prognosis; Carcinoma, ductal, breast; Breast neoplasms

\footnotetext{
Hospital do Servidor Público Estadual “Francisco Morato de Oliveira” Seção de Oncologia Pélvica e Mamária do Serviço de Ginecologia e Obstetrícia - São Paulo (SP), Brasil.

1 Pós-graduanda em Ciências da Saúde do Hospital do Servidor Público Estadual -HSPE- São Paulo (SP), Brasil

2 Coordenador da Seção de Oncologia Pélvica e Mamária do Serviço de Ginecologia e Obstetrícia do Hospital do Servidor Público Estadual - Hospital do Servidor Público Estadual - São Paulo (SP), Brasil.

Correspondência: Márcia Sanae Siroma

Rua Treze de Maio, 1178, apto. 11 - 01327-002 - São Paulo - SP - Telefone: (011) 5184-0444 - Fax (011) 5184-0445 - e-mail: santosiroma@ig.com.br 
Introdução

O câncer de mama permanece como o segundo tipo mais freqüente no mundo e o primeiro entre as mulheres. O número de casos novos esperados para o Brasil em 2006 é de 48.930, com incidência estimada de 52 casos a cada 100 mil mulheres ${ }^{1}$.

É a doença altamente heterogênea tanto biológica quanto clinicamente ${ }^{2}$. Esforços estão sendo feitos para diminuir a mortalidade pelo câncer de mama por meio da detecção precoce que permite tratamento e melhor prognóstico das mulheres afetadas ${ }^{3}$. A avaliação das características histológicas do tumor é utilizada rotineiramente para verificar a extensão da doença, sua provável evolução e para uma decisão terapêutica ${ }^{4,5}$. Contudo, algumas pacientes com características tumorais favoráveis apresentam rápida progressão da neoplasia e eventualmente algumas delas falecem em decorrência da mesma ou apresentam recorrência dentro de um período de cinco anos de seguimento ${ }^{6}$. Estas desigualdades podem ser devido a diferentes características da biologia tumoral $^{7}$.

Pesquisas em biologia molecular tem permitido a identificação de alterações em diferentes proto-oncogenes e genes supressores tumorais, os quais em várias combinações contribuem para o desenvolvimento dos tumores ${ }^{8}$. A alteração no gene supressor tumoral p53 é a mais comum descrita no câncer de mama, sugerindo o desempenho de um papel central no desenvolvimento desta doença maligna ${ }^{6,9-12}$.

O p53 é um gene supressor tumoral localizado no braço curto do cromossomo 17 e codifica uma proteína de 393 aminoácidos, a proteína p53, que controla a progressão de células da fase G1 para a fase $\mathrm{S}$ do ciclo celular, atuando como regulador negativo do crescimento celular em resposta a ocorrência de dano ao DNA com o intuito de restaurar a integridade genômica. A proteína p53 além de promover o reparo do DNA, atua também no controle da apoptose $\mathrm{e}^{5,7,13,14}$.

O gene p53 está comumente mutado no câncer humano e a sua proteína mutada perde a função, atuando como oncogene. Além da modificação de suas características funcionais, a meiavida, que em condições normais é de aproximadamente 20 minutos, aumenta para várias horas acumulando-se no núcleo celular, caracterizando-se a superexpressão. A proteína p53 mutada pode ser um passo crítico para o desenvolvimento de tumores. ${ }^{4}$.

Existem evidências de que a superexpres- são da p53, está envolvida na progressão do câncer de mama, e que ocorre sua associação com o pior prognóstico ${ }^{7,13-15}$. O valor prognóstico da presença da proteína p53 no carcinoma de mama é motivo para muitos estudos ${ }^{13}$. Alguns pesquisadores concluem que a expressão da proteína p53 não tem valor prognóstico independente ${ }^{2,6}$. No entanto, a importância do significado prognóstico do grau histológico tem sido demonstrado em inúmeros estudos ${ }^{11}$. Desta forma, a avaliação da combinação de fatores prognósticos pode ser de utilidade na prática clínica, para fazer-se estimativa do prognóstico de pacientes com câncer de mama $^{16}$.

Decidimos, então, avaliar a associação da presença da proteína p53 no carcinoma mamário ductal invasivo com o grau histológico e o grau nuclear, pois os dois últimos são fatores prognósticos, já estabelecidos para o câncer de mama.

\section{Métodos}

Desenvolvemos estudo retrospectivo, por meio de lâminas histológicas obtidas de 65 pacientes consecutivas do sexo feminino com carcinoma de mama ductal invasivo. Incluímos no estudo pacientes tratadas cirurgicamente no Departamento de Oncologia do Hospital São Cristóvão (São Paulo - Brasil). Tais pacientes foram atendidas no período de julho de 1999 até julho de 2001. Foram então selecionadas para este levantamento, somente carcinomas ductais invasivos. Excluímos os tumores diferentes dos ductais invasivos, especiais, in situ, recidivantes e metastáticos. A idade das pacientes variou de 41 a 90 anos, com média de 69,2 anos e mediana de 71 anos. Verificamos maior concentração $(55,4 \%)$ entre as faixas de 61 a 80 anos. A maioria das pacientes $(87,7 \%)$ estava na pós-menopausa. Quanto ao estadiamento clínico, 29 pacientes $(44,6 \%)$, foram classificadas em I, 23 pacientes (35,4\%), em IIa e as demais 13 (20\%) distribuíram-se em IIB, IIIA e IIIB. Nenhuma paciente recebeu tratamento prévio ao procedimento cirúrgico. Foram tratadas com cirurgia conservadora 43 pacientes $(66,2 \%)$ e $22(33,8 \%)$ com mastectomia. O tratamento adjuvante consistiu em radioterapia para todos os casos e hormonioterapia e quimioterapia conforme indicação clínica. O estudo obteve a aprovação do Comitê de Ética em Pesquisa do referido hospital.

A graduação histológica foi baseada no sistema descrito por Bloom e Richardson e modifi- 
cado por Elston e Ellis ${ }^{17}$. Neste sistema, consideram-se os aspectos de formação tubular, pleomorfismo nuclear e índice mitótico. Para cada parâmetro atribuímos os escores 1, 2 ou 3 . Desta forma, em relação à formação tubular, atribuiu-se escore 1, 2 e 3 quando esta foi encontrada em proporção maior que $75 \%$, entre 10 a $75 \%$ e menos que $10 \%$, do tumor formando túbulos, respectivamente, sempre com objetiva de 40 vezes. Na avaliação do pleomorfismo nuclear, nos servimos do seguinte critério: quando os núcleos eram pequenos, com discreto aumento no tamanho em comparação com o de células epiteliais normais, apresentando contornos e uniformidade da cromatina, foi atribuído 1 ponto ou grau nuclear 1 . Um escore de 2 pontos foi conferido quando os núcleos das células eram maiores que o normal, vesiculares com nucléolos evidentes, existindo moderada variação em ambos, no tamanho e na forma, consideramos grau nuclear 2. Quando os núcleos aparentavam bem maiores e bizarros com nucléolos múltiplos um escore 3 foi apropriado ou grau nuclear 3. A análise microscópica do padrão nuclear foi feita por meio de campos com objetiva de 40X (aumento de 400 vezes). O índice mitótico foi avaliado pela leitura de 10 campos também com objetiva de 40X, considerando-se escore 1 quando havia até 7 mitoses, escore 2 de 8 a 14 mitoses, e escore 3 se houvesse mais de 15 mitoses. Após a avaliação dos três aspectos histológicos, foi obtido uma somatória e, a partir dela, os carcinomas foram graduados em grau I (bem diferenciado): 3 a 5 pontos; grau II (moderadamente diferenciado): 6 e 7 pontos e grau III (pouco diferenciado): 8 e 9 pontos.

Utilizamos o método imuno-histoquímico e a estreptoavidina-biotina-peroxidase para avaliar a presença da proteína p53 $2,5,7,11,14,18$. Para a feitura da técnica imuno-histoquímica utilizamos materiais fixados em parafina por meio de lâminas histológicas, previamente tratadas com 3aminopropil-trietoxi-silano (ATPS), para evitar que os cortes de 3 a 5 micra descolassem no tratamento de recuperação antigênica, e após desparafinização, por meio de banhos de xilol, álcool absoluto, álcool 95\%, álcool 80\% e álcool 50\%, foram reidratados, mergulhados em tampão citrato $0,01 \mathrm{M} \mathrm{pH} 6,0$, para recuperação antigênica de 15 a 30 minutos no forno de microondas em potência variável de 1 a 10; após esfriar bloqueou-se a peroxidase endógena, utilizando-se banhos de peróxido de hidrogênio $\left(\mathrm{H}_{2} \mathrm{O}_{2}\right) 10$ volumes por 3 a 5 minutos cada. Os cortes foram então incubados 16 a 18 horas, à temperatura de $2^{\circ} \mathrm{C}$ a $8^{\circ} \mathrm{C}$ com o anticorpo primário $\mathrm{DO}-7$ especí- fico monoclonal mouse anti-human p53-protein (Laboratório Dako) diluído 1:100 em solução salina. Após este procedimento fez-se uma segunda incubação com um anticorpo secundário (antimouse/kit Dako), durante 30 a 40 minutos em estufa a $37^{\circ} \mathrm{C}$. A seguir, incubou-se com estreptoavidina (peroxidase conjugada/kit Dako), durante 30 minutos a $37^{\circ} \mathrm{C}$.

Para revelação foi necessário incubar por 2 a 10 minutos as lâminas em solução do substrato diaminobenzidina (DAB), 0,06 g em 100 mL de solução tampão PBS 0,01 M pH 7,4 (aproximadamente) com $2 \mathrm{~mL}$ de peróxido de hidrogênio $\left(\mathrm{H}_{2} \mathrm{O}_{2}\right) 10$ volumes. Corou-se com hematoxilina de Harris. As lâminas foram desidratadas em álcool 80\% - 95\%, à álcool absoluto. Foram passadas em álcool-xilol - xilol puro e montadas com Entellan e lamínulas. Utilizou-se para parâmetro um fragmento fortemente positivo para p53, como controle positivo e o mesmo material processado sem o anticorpo primário serviu de controle negativo. O material foi submetido à análise em microscopia com magnificação de 40 vezes, campos com diâmetro de 490 micra.

O tumor foi considerado positivo para a proteína p53 mutada se pelo menos 10\% dos núcleos estivessem corados. Foram avaliados aproximadamente 500 células de cada caso.

A análise histopatológica de toda amostra foi realizada por um único observador e revisada em duas diferente ocasiões.

Para avaliação estatística dos dados obtidos, todas as freqüências observadas foram colocadas numa tabela de contingência e, com a finalidade de comprovar a hipótese de pesquisa, testando a associação das variáveis, aplicamos o teste do $\chi^{2}$ de Pearson, ao nível de significância de 0,05.

\section{Resultados}

A expressão da proteína p53 foi verificada em $24(36,9 \%)$ e foi negativa em 41 casos $(63,1 \%)$. Ao avaliarmos o grau histológico, obtivemos 12 (18,5 \%), $35(53,8 \%)$ e $18(27,7 \%)$ carcinomas com grau histológico I, II e III respectivamente. Na análise do pleomorfismo nuclear, verificamos 8 (12,3\%), $34(52,3 \%)$ e $23(35,4 \%)$ carcinomas com grau nuclear 1,2 e 3 respectivamente.

Entre os carcinomas com expressão da proteína, observamos $3(12,5 \%), 8(33,3 \%)$ e 13 $(54,2 \%)$ casos com grau histológico I, II e III respectivamente. Na avaliação do pleomorfismo nuclear dentre os casos que expressaram a proteína, obtivemos 2 (8,3\%), $9(37,5 \%)$ e $13(54,2 \%)$ 
casos com grau nuclear 1, 2 e 3 respectivamente. Quanto ao grau de diferenciação histológica, verificamos que mais da metade dos carcinomas que expressaram a proteína p53, eram grau nuclear 3 e grau histológico III. Conforme pode ser avaliado nas Tabelas 1 e 2 .

Tabela 1 - Distribuição dos escores de grau nuclear, baseado no sistema descrito por Elston e Ellis ${ }^{17}$, em 65 carcinomas de mama ductal invasivo em relação à condição da proteína 553 analisada por técnica imuno-histoquímica

\begin{tabular}{cccc}
\hline Grau nuclear & $\begin{array}{c}\text { Pacientes } \\
\mathbf{n}(\%)\end{array}$ & $\begin{array}{c}\text { p53 positiva } \\
\mathbf{n}(\%)\end{array}$ & $\begin{array}{c}\text { p } 53 \text { negativa } \\
\mathbf{n}(\%)\end{array}$ \\
\hline 1 & $8(12,3 \%)$ & $2(8,3 \%)$ & $6(14,6 \%)$ \\
2 & $34(52,3 \%)$ & $9(37,5 \%)$ & $25(61 \%)$ \\
3 & $23(35,4 \%)$ & $13(54,2 \%)$ & $10(24,4 \%)$ \\
Total & 65 & 24 & 41 \\
\hline
\end{tabular}

n: número.

$p>0,05$ (não significante)

Tabela 2 - Distribuição do grau histológico, baseado no sistema descrito por Elston e Ellis ${ }^{17}$, em 65 carcinomas de mama ductal invasivo em relação a expressão da proteína p53, avaliada técnica imunohistoquímica

\begin{tabular}{cccr}
\hline Grau histológico & $\begin{array}{c}\text { Pacientes } \\
\mathbf{n}(\%)\end{array}$ & $\begin{array}{c}\text { p } 53 \text { positiva } \\
\mathbf{n}(\%)\end{array}$ & $\begin{array}{c}\text { p } 53 \text { negativa } \\
\mathbf{n}(\%)\end{array}$ \\
\hline I & $12(18,5 \%)$ & $3(12,5 \%)$ & $9(22,0 \%)$ \\
II & $35(53,8 \%)$ & $8(33,3 \%)$ & $27(65,8 \%)$ \\
III & $18(27,7 \%)$ & $13(54,2 \%)$ & $5(12,2 \%)$ \\
Total & $65(100 \%)$ & $24(100 \%)$ & $41(100 \%)$ \\
\hline
\end{tabular}

n: número.

$p=0,001$ (significante).

Ao aplicarmos os testes estatísticos para testarmos o nivel de correlação entre o grau nuclear e a positividade da proteína p53, obtivemos $\mathrm{p}=0,052$ ( $p>0,05)$, ou seja, não houve correlação significativa. Por outro lado, ao testarmos o nivel de significância entre o grau histológico e a positividade da proteína p53, obtivemos p=0,001 ( $\mathrm{p}<0,05)$, mostrando associação positiva entre as variáveis estudadas.

\section{Discussão}

A magnitude do problema do câncer de mama impõe, cada vez mais, a necessidade de conhecermos melhor os seus fatores prognósticos, tanto para orientar tratamento adequado assim como para entender sua evolução. Existem vários fatores prognósticos, alguns com valores já estabelecidos e seguros para serem utilizados na rotina clínica. Outros, entretanto, ainda constituem motivo para importantes controvérsias, sendo alvo de muitos estudos. Nos últimos anos têm-se verificado crescente interesse em marcadores moleculares, mas ainda não se definiu, de forma clara, a sua utilidade na prática clínica ${ }^{14,16}$.

A superexpressão da proteína p53 em câncer de mama é encontrada numa freqüência de 15 a $50 \%{ }^{6,10}$, conforme constatado pela maioria dos pesquisadores $5,7,11,14,15,19$. No presente estudo, o valor encontrado foi 36,9\%. Entretanto, alguns pesquisadores obtiveram freqüência maior que $61 \%{ }^{20-22}$.

Estas discrepâncias talvez possam ser explicadas pelo uso de anticorpos variados, diferentes critérios leitura, particularidades da técnica e heterogeneidade da população estudada ${ }^{6,9,23}$. Neste trabalho, utilizamos o anticorpo monoclonal DO-7 e interpretamos a expressão da proteína p53 quando mais que $10 \%$ das células neoplásicas apresentaram núcleos corados, critérios que estão em concordância com parte dos autores ${ }^{3,7,11,14,24}$. Outros pesquisadores, apesar de terem utilizado também o anticorpo monoclonal DO-7, adotaram como critério de interpretação para a expressão da proteína a partir de 5\% das células neoplásicas com núcleos $\operatorname{corados}^{8,22}$, sendo que num dos trabalhos, a porcentagem da superexpressão da p53 foi de $61,8 \%{ }^{22}$.

Anticorpos monoclonais Pab1801 Ig2a, e DO1 foram utilizados em alguns estudos ${ }^{4,9,12,15}$ e em uma destas pesquisas os autores ${ }^{12}$ verificaram $54,8 \%$ de superexpressão da p53, considerando casos positivos quando mais do que $10 \%$ de células tumorais estivessem coradas. Alguns pesquisadores utilizaram anticorpos policlonais RSp53 ou $\mathrm{CM}^{21,23,25,26}$ e obtiveram $68,2 \%, 40 \%, 54,8 \%$ e $21,4 \%$ de expressão da proteína p53, considerando os núcleos corados das células neoplásicas numa porcentagem de $10^{21}, 1^{23}, 20^{25}$ e $10 \%{ }^{26}$, respectivamente.

Alguns pesquisadores graduaram a coloração dos núcleos das células neoplásicas atribuindo escores de $1+, 2+$ ou $3+$, conforme a quantidade de células expressando a proteína, entretanto, ao final, indicaram a totalidade encontrada da expressão da proteína, ou seja, 36,2 e 19,28 \% ${ }^{13}$.

Em relação ao uso de anticorpos monoclonais e policlonais, não percebemos a diferença entre empregar um ou outro, pois basicamente a técnica do procedimento é semelhante independente do anticorpo e as diluições também não dependeram do tipo, variando de 1:50, 1:70, 1:100, 1:120, 1:200, 1:300, 1:400. Para nosso estudo utilizamos a diluição 1:100 assim como alguns autores ${ }^{2,5,11,14}$.

A técnica imuno-histoquímica, embora conceitualmente avançada, podem sofrer varia- 
ções devido aos reagentes utilizados, diversidade de anticorpos e a técnica de recuperação antigênica, conservação e fixação do material não é padronizada entre as diferentes instituições ${ }^{16}$. $\mathrm{O}$ uso de materiais fixados e guardados em arquivos, embora comum, é problemático por causa da possibilidade da degradação interferindo na intensidade da coloração ${ }^{16}$. Todavia, a técnica imunohistoquímica representa o procedimento mais adequado para avaliar a expressão da proteína p53 no câncer de mama ${ }^{12}$.

Optamos em avaliar os carcinomas ductais invasivos, uma vez que este é o tipo histológico mais comum pois consideramos que cada tipo apresenta uma particularidade. Por outro lado, o intuito foi organizar amostragem com característica homogênea. Alguns pesquisadores também estudaram somente carcinomas do tipo ductal invasivo $^{5,6,15,23}$. Outros pesquisaram carcinoma ductal in situ ${ }^{19,22,24}$. Contudo, outros autores incluíram mais de um tipo histológico em seus trabalhos, chegando porém, à mesma conclusão quanto à presença da p53 estar associada ao grau histológico. Foram incluídas na amostragem carcinomas ductais invasivos, lobulares invasivos, medulares e outros ${ }^{11,26,27}$.

Quanto à análise do grau histológico, utilizamos o sistema descrito por Bloom e Richardson e atualizado por Elston e Ellis que é importante método para o diagnóstico histopatológico ${ }^{17}$. A abordagem morfológica do grau de diferenciação, apesar de resultar em uma informação prognóstica útil no câncer de mama, apresenta problemas devido à falta de reprodutibilidade entre os patologistas $^{28}$. É essencial ter um protocolo definido com os critérios de avaliação e que seja aderido pelos observadores para melhorar a reprodutibilidade ${ }^{17}$.

Neste estudo relacionamos a expressão da proteína p53 com o grau de diferenciação. Em nossa amostragem, os graus histológicos apresentaramse relacionados à superexpressão da proteína p53, seguindo o que é encontrado na literatura ${ }^{6,11,19,23}$. Porém, dentre os elementos que compõem o grau histológico, o grau nuclear vem ganhando destaque, pois outro método que também é utilizado para a graduação dos carcinomas de mama é aquele no qual apenas o pleomorfismo nuclear é avalia$\mathrm{do}^{28}$. Partindo desta observação e sabendo que a graduação histológica depende dos escores do grau nuclear, resolvemos avaliar cada um desses aspectos em relação à presença da p53 e, de certa forma, testando sua sensibilidade.

Em nossa pesquisa verificamos que, dentre os carcinomas que expressaram a proteína p53, obtivemos a maior porcentagem $(54,2 \%)$ com grau histológico III, e quanto ao grau nuclear observa- mos de forma coincidente $(54,2 \%)$ grau 3 . Analisando estes resultados, percebemos que o maior predomínio da superexpressão da p53 foi verificado em carcinomas com alto grau histológico e também com alto grau nuclear. Entretanto, quando aplicamos o teste estatístico, com a finalidade de comprovar a hipótese da pesquisa, obtivemos como resultado uma relação significativa entre o grau histológico e a presença da p53. Porém, no tocante ao grau nuclear, não se observou associação significante, mas observamos tendência para tal. Diante desses resultados podemos afirmar que a avaliação da presença da proteína p53 no carcinoma de mama ductal invasivo é de valor quando relacionada ao grau histológico. Todavia, não se dispõe ainda, na literatura, de muitos trabalhos referentes à associação da expressão da proteína p53 com grau nuclear somente, e os resultados são controversos. Assim, alguns pesquisadores não observaram associação significativa entre a expressão da p53 e o grau nuclear e nem com o grau histológico ${ }^{19}$, contrariando, em relação ao segundo item, a maior parte dos pesquisadores e também a nossa pesquisa.

Por outro lado, outros autores ${ }^{21,24}$, verificaram associação significativa entre a expressão da p53 e o grau nuclear. Tal discordância em relação aos nossos resultados pode dever-se ao fato, de que em um dos estudos ${ }^{24}$, apesar de, como nós, terem utilizado anticorpos monoclonais, incluíram em sua amostragem, apenas carcinomas ductais in situ, ao contrário da nossa casuística na qual estudamos carcinomas ductais invasivos. Por sua vez, em outra pesquisa ${ }^{21}$ utilizaram anticorpos policlonais diversos dos nossos, além de incluírem na amostragem carcinomas intraductais e invasivos ao mesmo tempo.

Concluímos que a proteína p53 apresenta associação significativa com o grau histológico em carcinomas ductais invasivos. Sabe-se que, para utilizar qualquer parâmetro prognóstico na prática clínica, é necessário embasamento em pesquisa de literatura. A associação entre p53 e grau histológico vem sendo comprovada por várias pesquisas, porém relacionado ao grau nuclear não se tem ainda uma definição, sendo necessários outros estudos para melhor esclarecimento.

\section{Referências}

1. Ministério da Saúde. Secretaria de Atenção à Saúde. Instituto Nacional de Câncer [homepage na Internet]. Estimativa 2006: Incidência de câncer no Brasil. Rio de Janeiro; 2006 [citado 2006 Maio 29]. Disponível em: http://www.inca.gov.br/estimativa/2006/ 
2. Gago FE, Tello OM, Biblasi AM, Ciocca DR. Integration of estrogen and progesterone receptors with pathological and molecular prognostic factors in breast cancer patients. Steroid Biochem Molec Biol. 1998;67(5-6):431-37.

3. Goel MM, Goel R, Mehrotra A, Nath P, Agarwal PK, Singh $\mathrm{K}$, et al. Immunohistochemical localization and correlation of p53 and PCNA expression in breast carcinoma. Indian J Exp Biol. 2000;38:225-30.

4. Leong ACK, Hanby AM, Potts HWW, Tan DSP, Skilton $\mathrm{D}$, Ryder K, et al. Cell cycle proteins do not predict outcome in grade I infiltrating ductal carcinoma of the breast. Int $J$ Cancer. 2000;89(1):26-31.

5. Gao RJ, Bao H, Yang Q, Cong $\mathrm{Q}$, Song J, Wang L. The presence of serum anti-p53 antibodies from patients with invasive ductal carcinoma of breast: Correlation to other clinical and biological parameters. Breast Cancer Res Treat. 2005;93(2):111-5.

6. Erdem O, Dursun A, Coskun U, Gunel. The prognostic value of p53 and c-erbB-2 expression proliferative activity and angiogenesis in node-negative breast carcinoma. Tumori. 2005;91(1):46-52.

7. Choi DH, Kim S, Rimm DL, Carter D, Haffty BG. Immunohistochemical biomarkers in patients with early-onset breast carcinoma by tissue microarray. Cancer J. 2005; 11(5):404-11.

8. Michalides R, Hageman P, Tinteren HV, Houben L, Wientjens E, Klompmaker R, et al. A clinicopathological study on overexpression of cyclin D1 and of p53 in a series of 248 patients with operable breast cancer. Br J Cancer. 1996;73(6):728-34.

9. Nakopoulou L, Michalopoulou A, Giannopoulou I, Tzonou A, Keramopoulos A, Lazaris A. bcl-2 protein expression is associated with a prognostically favourable phenotype in breast cancer irrespective of p 53 immunostaining. Histopathology. 1999;34(4):310-19.

10. Done SJ, Eskandarian S, Bull S, Redston M, Andrulis IL. P 53 missense mutations in microdissected high-grade ductal carcinoma in situ of the breast. J Natl Cancer Inst. 2001;93(9):700-4.

11.Cummings MC, Walsh MD, Hohn BG, Bennett IC, Wright RG. Occult axillary lymph node metastases in breast cancer do matter. Am J Surg Pathol. 2002;26(10):1286-95.

12. Kostler WJ, Brodowicz T, Hudelist G, Rudas M, Horvat R, Steger GG, et al. The efficacy of trastuzumab in Her-2/neu-overexpressing metastatic breast cancer is independent of p53 status. J Cancer Res Clin Oncol. 2005;131(7):420-8.

13. Bukholm IRK, Husdal A, Nesland JM, Langerod A, Bukholm G. Overexpression of ciclin A overrides effect of p53 alterations in breast cancer patients with long follow-up time. Breast Cancer Res Treat. 2003;80(2):199-206.

14. Ribeiro-Silva A, Ramalho LNZ, Garcia SB, Zucoloto $\mathrm{S}$. The relationship between p63 and p53 expression in normal and neoplastic breast tissue. Arch Pathol Lab Med. 2003;127(3):336-40.
15. Yamashita H, Nishio M, Toyama T, Sugiura H, Zhang Z. Coexistence of HER 2 over- expression and p53 protein accumulation is a strong prgnostic molecular marker in breast cancer. Breast Cancer Res. 2004;6(1):R24-30.

16. Mirza AN, Mirza NQ, Vlastos G, Singletary E. Prognostic factors in node-negative breast cancer. Ann Surg. 2002;235(1):10-26.

17.Elston CW, Ellis IO. Pathological prognostic factors in breast cancer. I. The value of histological grade in breast cancer: experience from a large study with long term follow-up. Histopathology. 1991;19:403-10.

18. Scawn R, Shousha S. Morphologic spectrum of estrogen receptor-negative breast carcinoma. Arch Pathol Lab Med. 2002;126(3):325-30.

19. Oh Yl, Choi JS, Song SY, Ko YH, Han BK, Nam SJ, et al. Expression of p2 $1^{\text {Waf1 }}, \mathrm{p} 27^{\text {Kip } 1}$ and cyclin D1 proteins in breast ductal carcinoma in situ: Relation with clinicopathologic characteristics and with p53 expression and estrogen receptor status. Pathol Int.2001;51(2):94-9.

20. Kesari AL, Chellam VG, Madhavan J, Nair PP, Ahmed I, Madhavan J, et al. p53 tumor suppressor protein and tissue proliferative fraction in infiltrating ductal carcinoma.J Surg Oncol.1997;65:159-63.

21. Moriya T, Sakamoto K, Sasano H, Kawanaka M, Sonoo $\mathrm{H}$, Manabe $\mathrm{T}$, et al. Immunohistochemical analisis of Ki-67, p53, p21, and p27 in benign and malignant apocrine lesions of the breast: its correlation to histologic findings in 43 cases. Mod Pathol. 2000;13(1):13-8.

22. Leal C, Henrique R, Monteiro P, Lopes C, Bento MJ. Apocrine ductal carcinoma in situ of the breast: histologic classification and expression of biologic markers. Hum Pathol. 2001;32:487-93.

23. el-A Helal T, Khalifa A, Kamel AS. Immunohistochemical expresión of p53 and c-erbB2 proteins in breast cancer in Egypt. Anticancer Res. 2000;20(3B):2145-50.

24. Rajan PB, Scott DJ, Perry RH, Griffith CD. p53 protein expression in ductal carcinoma in situ (DCSI) of the breast. Breast Cancer Res Treat. 1997;42(3):283-90.

25. Pietilainen T, Lipponen P, Aaltomaa S, Eskelinen M, Kosma VM, Syrjanen K. Expression of p53 protein has no independent prognostic value in breast cancer. J Pathol. 1995;177(3):225-32.

26. Iwaya K, Tsuda H, Fukutomi T, Tsugane S, Suzuki M, Hirihashi S. Histologic grade and p53 imnunoreaction as indicators of early recurrence of node-negative breast cancer. Jpn J Clin Oncol. 1997;27(1):6-12.

27. Haerslev T, Jacobsen GK. An immunohistochemical study of p53 with correlations to histopathological parameters, c-erbB2, proliferatin cell nuclear antigen, and prognosis. Hum Path.1995; 26(3):295-301.

28. Eisenberg ALA, Koifman S. Fatores prognósticos do câncer de mama. Rev Bras Mastol. 2000;10(2):75-87. 